\title{
EDITORIAL
}

\section{COVID -19 Infection in Children}

Coronavirus disease 2019 (COVID-19) caused by Severe Acute Respiratory Syndrome Coronavirus-2 (SARS$\mathrm{CoV}-2$ ) is proven to be the biggest public health crises of recent times ${ }^{1}$.As per the World Health Organization's (WHO) update dated 21st June 2021, there have been 1,78,202,610 confirmed cases and 3,865,738 deaths worldwide $^{2}$. The severity of corona virus disease specific acute respiratory infection vary in different age groups; the elderly are likely to have severe disease, children are relatively spared till-date ${ }^{3}$. Several differences in the pathogenesis of COVID-19 between children and adults have been proposed to explain these differences ${ }^{4}$.

SARS-CoV-2 enters respiratory epithelial cells by attaching to angiotensin converting enzyme-2 (ACE-2) via S-protein. ${ }^{5}$ Higher infectivity of SARS-CoV-2 can be explained by higher affinity of SARSCoV-2 for ACE-2 than other corona viruses. ${ }^{6} \mathrm{ACE}-2$ is present on apical membranes of oral, nasal, oropharyngeal and nasopharyngeal mucosal epithelium, alveolar epithelium, endothelial cells of blood vessels and heart, renal tubules, and enterocytes in small intestine ${ }^{7}$. After entering pneumocytes, SARS-CoV-2 downregulates ACE-2 expression and decreases angiotensin-2 metabolism. Elevated angiotensin-2 increases pulmonary vascular permeability and inflammation, hence worsening of lung injury. ${ }^{8,9}$ High levels of ACE-2 activity and increasing metabolism of angiotensin- 2 in children could be protective for COVID-19, leading to less severe disease in this age group compared to elderly.

The protective immunological mechanisms in children against COVID 19 is explained by the phenomenon of trained immunity which is the functional re-programming of innate immune cells to a more activated state following initial antigen stimulation (infections or vaccination); there is enhanced transcription of IL- ${ }^{2}$, IL-6 and TNF\pm genes due to metabolic re-programming and epigenetic changes characterized by acetylation and demethylation. It can affect progenitor cells of myeloid and monocyte cell lines as well as local cells (lung macrophages and dendritic cells). ${ }^{10}$ Based on this phenomenon it has been postulated that countries with routine Bacille Calmette-Guerin (BCG) vaccination have less COVID-19 related morbidity and mortality. ${ }^{11}$

Cross Immunity to other coronavirus infections offers protection against corona virus disease 19. As coronavirus infections are common causes of URI in children, protective role of antibodies from other coronavirus infections against SARS-CoV-2 cannot be ruled out. Cross-reactive antibodies (CR3022) specific for domain of SARS-CoV-1 and SARS-CoV-2 showed low affinity for SARS-CoV-2 . ${ }^{12}$ Following influenza infection, antibodies against conserved epitopes of influenza have been shown to have heterosubtypic influenza immunity. ${ }^{13,14}$

Developmental changes in Immunity as obvious in neonates and elderly underlie disease severity in these age group. Predominant response to infectious stimulus in young infants is innate response and less prominent adaptive response. An inadequate adaptive response could explain worse course of illness seen in COVID-19 affected young infants compared to older children. Also, maternal antibodies offering protection for neonates and young infants, are unlikely to act against novel viruses like SARSCoV-2. ${ }^{15}$

However good regenerative capacity of the lung could explain overall less severity and early recovery of COVID-19 in children compared to older patients. Also due to greater upper airway resistance in children, aerosol particles deposit more in tracheobronchial tree than alveoli. ${ }^{16}$ This may explain bronchiolitis like infections and less pneumonia with SARS-CoV-2 infection in children.

As most of morbidities ( heart disease, cardiovascular disease, smoking, obesity) in adults causing upregulation of ACE-2 are not commonly seen in children, children are placed in a favourable position. For children common comorbid conditions proven to be fatal for other viral respiratory tract infections like presence of prematurity, co-existing heart disease, 
recurrent wheezing/asthma, neurological disorder, genetic disorder are considered risk factor for severe corona virus disease. ${ }^{17,18}$

The spectrum of disease manifestation ranges from asymptomatic through mild /moderate symptoms to severe / critical diasease. About $4 \%$ of virologically confirmed cases are asymptomatic infection, and this rate almost certainly underestimates the true rate of asymptomatic infection because many asymptomatic children are unlikely to be tested. ${ }^{19}$

Asymptomatic children may play a major role in community-based viral transmission. Available data suggest that children may have more upper respiratory tract involvement (including nasopharyngeal carriage) rather than lower respiratory tract involvement. Also fecal shedding of virus in the stool continues for several weeks after diagnosis, ${ }^{20}$ leading to concern about fecaloral transmission of the virus, particularly for infants and children who are not toilet trained, and viral replicates in the gastrointestinal tract. ${ }^{21}$ Prolonged shedding in nasal secretions and stool has substantial implications for community spread in child care centers, in schools, and in the home.

Foe the symptomatic children requiring hospital admission the most common presenting symptoms are fever(70\%; ), cough (39\%; ), nausea/ vomiting (32\%; ), and shortness of breath $(30 \%)^{22}$

In the largest child case series of 2,143 children diagnosed with laboratory-verified or clinically diagnosed ${ }^{23}$, more than $90 \%$ children diagnosed with laboratory-verified or clinically diagnosed COVID-19 had asymptomatic, mild or moderate disease. Of the remainder, $5.2 \%$ had severe disease and $0.6 \%$ had critical disease. ${ }^{23}$ Severe disease was defined as dyspnoea, central cyanosis and an oxygen saturation of less than $92 \%{ }^{23}$ Critical disease required respiratory failure, sometimes with acute respiratory distress syndrome, shock and signs of multi-organ failure, such as encephalopathy, heart failure, abnormal coagulation and acute renal failure.

The prevalence of severe and critical disease was $10.6 \%$ in children aged $<1$ year at diagnosis, $7.3 \%$ in $1-5$ year group, $4.2 \%$ in $6-10$ years , $4.1 \%$ in $11-15$ years and $3 \%$ in $16-17$ years age group. ${ }^{23}$ Only $1.8 \%$ required intensive care and all of those had underlying diseases. The comorbid conditions were hydronephrosis, leukaemia with chemotherapy and intussusception. ${ }^{24}$

Laboratory diagnosis of COVID 19 in children is mostly unremarkable. Full Blood counts are normal in most of the cases; leucopenia, neutropenia or lymphopenia are less noted. Abnormal CRP, procalcitonin, liver enzymes or CPK also present in few cases. However good number of paediatric patient can have abnormal CT findings characterics of COVID pneumonia even in asymptomatic or mild to moderate clinical category. ${ }^{25}$

Multisystem inflammatory syndrome in children (MISC) associated with the coronavirus disease 2019 (COVID-19) is a new concern emerging as a severe presentation of COVID-19 in children. This concern emerged from England in April 2020 with the introduction of an increasing number of cases similar to Kawasaki disease (KD). ${ }^{26}$ There were also similar case reports from other European countries, Canada, and the United States soon thereafter. Centers for Disease Control and Prevention (CDC) named this emerging condition as a multisystemic inflammatory syndrome in children (MIS-C). ${ }^{27}$ Although this new entity shared some similar features with KD, reported clinical and laboratory findings were found different. For instance, myocardial and gastrointestinal (GI) involvement were more prominent in patients with MIS-C, and laboratory findings such as lymphopenia and thrombocytopenia were common, which were incontrast with features consistent with $\mathrm{KD}$.

A targeted surveillance for MIS-C from March 15 to May 20, 2020, in pediatric health centers across the United States showed that the organ involvement in MIS-C were GIT( $92 \%$ ) followed by CVS (80\%), hematologic $(76 \%)$, mucocutaneous $(74 \%)$, and respiratory $(70 \%)$. The median duration of hospitalization was 7 days (interquartile range, 4 to 10); About $80 \%$ required intensive care, $20 \%$ mechanical ventilation, $48 \%$ vasoactive support. Mortality was $2 \%$. Thus the study concluded that multisystem inflammatory syndrome in children associated with SARS-CoV-2 led to serious and life-threatening illness in previously healthy children and adolescents. ${ }^{28}$

During this era of COVID pandemic Bangladesh is also experiencing COVID 19 among paediatric patients. In line with global picture the rate, severity and COVID related fatality is less in children. Hospital care of the 
infected children are according to national guideline based on standard international guidelines. The healthcare professionals are getting confident over time for managing admitted children. However published reports and research papers on paediatric COVID are scarce. The article on " clinical profile and outcome of Covid-19 In children at a tertiary hospital, Dhaka " which is published in this issue of Journal of Bangladesh College of Physicians and Surgeons(BCPS) is a remarkable step forward to share experience of epidemiological and clinical profile of admitted Covid19 children in Combined Military Hospital(CMH), Dhaka. This has given us some information of Covid-19 infection in paediatric population in a defined population. In order to understand the magnitude of the problem and to develop standard management protocol; it is now imperative to conduct more studies in Paediatric population in Bangladesh.

Though SARS COV2 infection causes less fatality among children, the need to vaccination cannot be underestimated . Currently CDC recommend COVID vaccine for children above 12 years. But it should be duly extended to cover other paediatric age group.

Also there is need to conduct basic and clinical research on paediatric COVID 19 to study risk factors for severe SARS-CoV-2 infection in children, to identify population most appropriate for clinical trials and administration of antiviral therapies and vaccines (once available). Facilitation and description of paediatric autopsies and post-mortem lung biopsies is needed for defining patterns of lung injury. Also development of potent anti-viral agents should be expedited.

(J Bangladesh Coll Phys Surg 2021; 39:) DOI: https://doi.org/10.3329/jbcps.v39i3.54157

\section{Prof. Mohammod Shahidullah}

Professor \& Chairman

Department of Neonatology

Bangabandhu Sheikh Mujib Medical University

\section{References:}

1. Jin Y, Yang H, Ji W, et al. Virology, epidemiology, pathogenesis, and control of COVID-19. Viruses. 2020;12:e372.

2. WHO COVID-19 Dashboard. Available at: https:// covid19.who. int/ . Accessed 22June 2021.
3. Wu Z, McGoogan JM. Characteristics of and important lessons from the coronavirus disease 2019 (COVID-19) outbreak in China: summary of a report of 72314 cases from the Chinese Center for Disease Control and Prevention. JAMA. 2020;323: 1239. https://doi.org/ 10.1001/jama.2020.2648.

4. Lee P-I, Hu Y-L, Chen P-Y, Huang Y-C, Hsueh P-R. Are children less susceptible to COVID-19? J Microbiol Immunol Infect. 2020. https://doi.org/10.1016/j.jmii.2020.02.011. 5

5. Hoffmann M, Kleine-Weber H, Schroeder S, et al. SARSCoV-2 cell entry depends on ACE2 and TMPRSS2 and is blocked by a clinically proven protease inhibitor. Cell. 2020;181:271-80. 28. Wrapp D, Wang N, Corbett KS, et al. Cryo-EM structure of the 2019-nCoV spike in the prefusion conformation.

6. Wrapp D, Wang N, Corbett KS, et al. Cryo-EM structure of the 2019-nCoV spike in the prefusion conformation. Science.2020;367:1260-3.

7. Song R, Preston G, Yosypiv IV. Ontogeny of angiotensin converting menzyme 2. Pediatr Res. 2012;71:13-9.

8. de Wit E, van Doremalen N, Falzarano D, Munster VJ. SARS and MERS: recent insights into emerging coronaviruses. Nat RevMicrobiol. 2016;14:523-34.

9. Imai $\mathrm{Y}, \mathrm{Kuba} \mathrm{K}$, Rao S, et al. Angiotensin-converting enzyme 2 protects from severe acute lung failure. Nature. 2005;436:112-6.

10. Netea MG, Domínguez-Andrés J, Barreiro LB, et al. Defining trained immunity and its role in health and disease. Nat Rev Immunol. 2020. https://doi.org/10.1038/s41577020-0285-6

11. Miller A, Reandelar MJ, Fasciglione K, Roumenova V, Li Y, Otazu GH. Correlation between universal BCG vaccination policy and reduced morbidity and mortality for COVID19: An epidemiological study. medRxiv. 2020; https:// doi.org/10.1101/2020.03.24. 20042937.

12. Yuan $\mathrm{M}, \mathrm{Wu} \mathrm{NC}, \mathrm{Zhu} \mathrm{X}$, et al. A highly conserved cryptic epitope in the receptor-binding domains of SARS-CoV-2 and SARS-CoV. Science. 2020:eabb7269. https://doi.org/ 10.1126/science.abb7269.

13. Baumgarth N. How specific is too specific? B-cell responses to viral infections reveal the importance of breadth over depth. Immunol Rev. 2013;255:82-94.

14. Braciale TJ, Hahn YS. Immunity to viruses. Immunol Rev. 2013;255:5-12.

15. Pou C, Nkulikiyimfura D, Henckel E, et al. The repertoire of maternal anti-viral antibodies in human newborns. Nat Med. 2019;25: 591-6.

16. Phalen RF, Oldham MJ, Beaucage CB, Crocker TT, Mortensen JD. Postnatal enlargement of human tracheobronchial airways and implications for particle deposition. Anat Rec. 1985;212:368-80. 
17. Geoghegan S, Erviti A, Caballero MT, et al. Mortality due to respiratory syncytial virus. Burden and risk factors. Am J Respir Crit Care Med. 2016;195:96-103.

18. Wong KK, Jain S, Blanton L, et al. Influenza-associated pediatric deaths in the United States, 2004-2012. Pediatrics. 2013;132:796-804.

19. Dong Y, Mo X, Hu Y, et al. Epidemiology of COVID-19 among children in China. Pediatrics. 2020;145(6):e20200702

20. Cai J, Xu J, Lin D, et al. A case series of children with 2019 novel coronavirus infection: clinical and epidemiological features [published online ahead of print February 28, 2020]. Clin Infect Dis. doi:10.1093/cid/ciaa198

21. Xiao F, Tang M, Zheng X, Liu Y, Li X, Shan H. Evidence for gastrointestinal infection of SARS-CoV-2 [published online ahead of print March 3, 2020]. Gastroenterology. doi:10.1053/ j.gastro.2020.02.055

22. Swann OV, Holden KA, Turtle L, et al.Clinical characteristics of children and young people admitted to hospital with covid-19 in United Kingdom: prospective multicentre observational cohort study. BMJ 2020;370:m3249 | doi: 10.1136/bmj.m3249

23. Dong Y, Mo XI, Hu Y, et al. Epidemiological characteristics of 2143 pediatric patients with 2019 coronavirus disease in China. Pediatrics. 2020;16:16
24. Yang PU, Liu P, Li D, et al. Corona Virus Disease 2019, a growing threat to children? J Infect. 2020;03:03. https:// doi.org/10.1016/j. jinf.2020.02.024. 4

25. Liguoro I, Pilotto C, Margherita Bonanni et al. SARSCOV-2 infection in children and newborns: a systematic review. European Journal of Pediatrics 2020; published online https://doi.org/10.1007/s00431-020-03684-7

26. Ramcharan T, Nolan O, Lai CY, et al. Paediatric Inflammatory Multisystem Syndrome: temporally associated with SARS-CoV-2 (PIMS-TS): Cardiac features, management and short-term outcomes at a UK Tertiary Paediatric Hospital. Pediatr Cardiol. 2020;41:1391-1401. doi: 10.1007/s00246-020-02391-2. [PMC free article] [PubMed] [CrossRef] [Google Scholar]

27. Center for Disease Control and Prevention, C.f.P.a.R.M.I.S.i.C.M.-C.A.w.C.D.C.- Clinician Outreach and Communication (COCA) Webinar. Available from: https://emergency.cdc.gov/coca/calls/2020/ callinfo_051920.asp?delivery Name=USCDC_1052DM28623.

28. Feldstein LR, Rose EB, Horwitz SM, et al..Multisystem Inflammatory Syndrome in U.S. Children and Adolescents. N Engl J Med 2020 Jul 23;383(4):334-346. doi: 10.1056/ NEJMoa2021680. Epub 2020 Jun 29. 